\section{Un asentamiento costero del norte semiárido chileno. La memoria de su ecosistema*}

\section{A coastal settlement of the chilean semi-arid north. the memory of its ecosystem}

\author{
María Eugenia Solari
}

\section{Resumen}

Para la construcción de una mirada histórica del litoral de Los Vilos, ubicado en el norte semiárido

\footnotetext{
Proyecto Fondecyt $\mathrm{N}^{\circ}$ 1171309: Condicionamientos socioambientales y económico-culturales de la producción y la intermediación en el espacio pesquero-artesanal chileno. Una investigación antropológica sobre los límites de la transformación social.

** Instituto de Estudios Antropológicos. Laboratorio de Arqueobotánica e Historia Ambiental, Universidad Austral de Chile. Campus Isla Teja, casilla 567, Valdivia. Correo electrónico: msolari@uach.cl
}

de Chile, se intenta consensuar los conocimientos académicos y locales, vinculando los archivos arqueológicos, históricos y visuales con la memoria de sus habitantes. Ninguno de estos saberes es considerado subalterno, formando todos ellos un palimpsesto de significados que aportan al estudio de la memoria de ese territorio y reflejan la identidad ecosistémica de quienes habitan y trabajan en su litoral. En los relatos de los actuales pescadores vileños se reiteran elementos de su pasado nómada marino, que ellos adscriben a una tradición "changa" de la cual se sienten parte.

Palabras clave: Historia ambiental, conocimientos locales y académicos, memoria ecosistémica, litoral de Los Vilos

\begin{abstract}
For the construction of a historical view of the Los Vilos coastline, located in the semiarid north of Chile, an attempt is made to reach consensus on academic and local knowledge, linking the archaeological, historical and visual archives with the memory of its inhabitants. None of this knowledge is considered subaltern, forming all of it a palimpsest of meanings that contribute to the study of the memory of that territory and reflect the ecosystemic identity of those who inhabit and work on its coastline. In the stories of the present-day vileño fishermen, elements of their marine nomadic past are reiterated, which they ascribe to a "changa" tradition of which they feel a part of.
\end{abstract}

Key words: Environmental history, local and academic knowledge, ecosystem memory, Los Vilos coastline. 


\section{Introducción}

La construcción de la historia ambiental del litoral de Los Vilos puede efectuarse desde los conocimientos científicos, los documentos históricos y la memoria de sus habitantes, principalmente de sus pescadores, los que se sienten depositarios de una tradición de los grupos changos históricos, habitantes del litoral del norte semiárido. Enfatizando con ello la importancia de transitar libre y extensivamente por su litoral, accediendo a la riqueza en especies marinas (pesca y recolección). Esta tradición changa está actualmente siendo reivindicada por algunos grupos familiares de pescadores del norte semiárido que han solicitado ser reconocidos como "etnia chilena", instancia que se encuentra en trámite en el Senado de la República.

En paralelo, en la memoria urbana de Los Vilos, resuenan sus múltiples mutaciones socioeconómicas. Habitantes e historiadores hacen hincapié principalmente en un perdido pasado glorioso, el de su condición de Puerto Menor, cerrado en la década del 50', convirtiéndose posteriormente en un espacio pesquero artesanal de importancia, que es recordado y anhelado por sus pescadores y comerciantes (Vidal Gormaz 2013; Goicovic 2013; Rivera 2014; Fuenzalida 2016; Delgado 2017). Aun así, el puerto sigue presente, materialmente en sus ruinas y en el relato de un vileño (imagen 1 ).

\begin{abstract}
Tengo mucha memoria de recordarme como fue toda esa transformación que fue teniendo la comuna de Los Vilos, porque vivíamos antes de este puerto abierto $\mathrm{y}$, cuando se cerró, quedamos solamente viviendo de la pesca, (...) es como hasta el año 70 más o menos que tuvimos esa manera de vivir acá.
\end{abstract}

La descripción del puerto efectuada por Vidal Gormaz en 1880, da cuenta de una prosperidad
Imagen 1: ruinas de antiguo muelle del puerto de Los Vilos
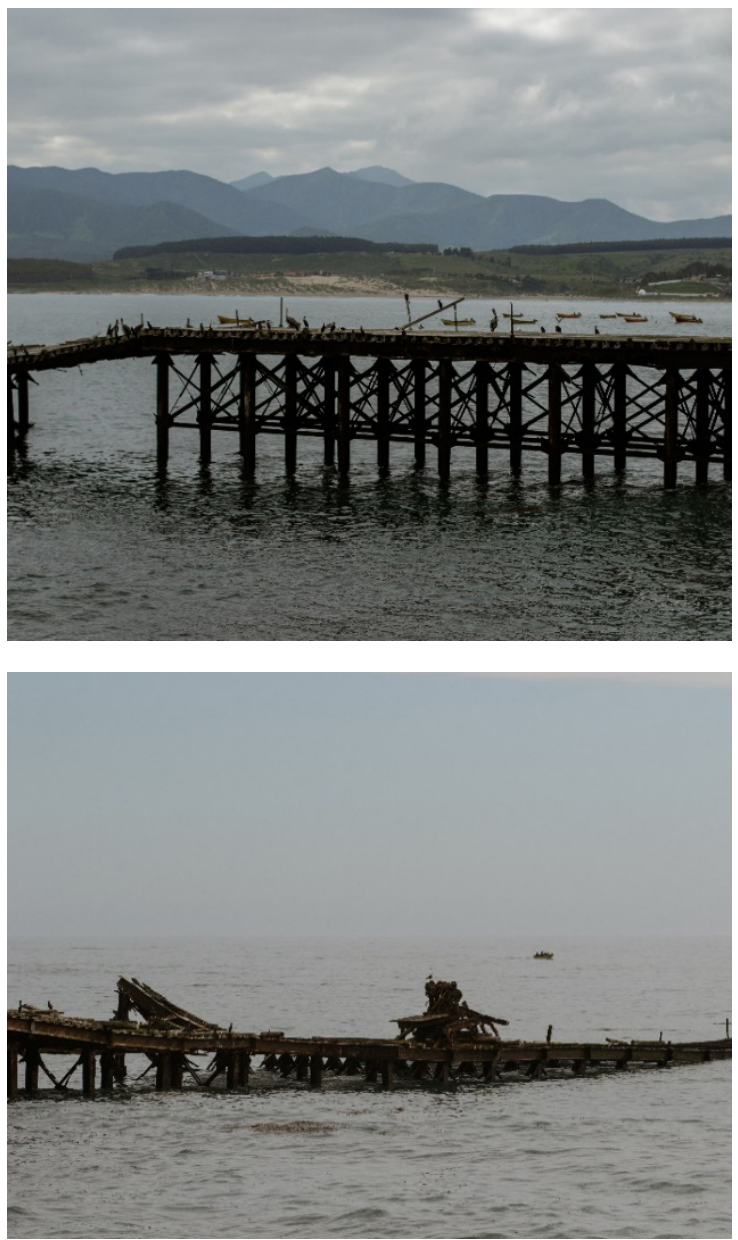

Fuente: Foto: A. Utreras.

no tan solo de la ciudad, sino que atañe a toda la provincia agrícola y minera:

(...) el puerto es importante y progresa rápidamente. Numerosos buques nacionales i estranjeros arriban a los Vilos para cargar ejes de cobre, trigo, harina i frutos de todo jénero, tocan también allí muchos vapores costaneros, algunos con itinerario fijo, que conducen pasajeros e introducen mercaderías de todas clases y 
estraen frutos del pais. Embarcaciones menores para servicio de la rada se encuentran en cantidad suficiente (Vidal Gormaz 2013: 205).

De este modo, múltiples han sido los atributos que ha tenido el litoral vileño desde el siglo XIX: puerto menor minero, espacio de tránsito de mercancías y habitantes, de intercambio entre una costa rica en especies marinas y el interior agrícola-ganadero, perdurable espacio pesquero artesanal con sus múltiples caletas y varaderos $\mathrm{y}$, en este siglo XXI, la pérdida de su condición de caleta(s) altamente productivas con la instalación de un muelle de embarque de concentrado en Punta Chungo, perteneciente a la Minera Pelambres, unido a la ley de pesca, que establece las áreas de manejo, parcelando de este modo sus espacios de explotación.

\section{Planteamientos teóricos}

A partir de los conocimientos locales y académicos (sensu Briones 2013), en este artículo se transitará por la historia ambiental de este territorio, para tratar de comprender el conjunto de las manifestaciones, tanto prácticas como simbólicas o de adscripción, que se encuentran asociadas a la economía de base pesquero-artesanal de Los Vilos. Estos conocimientos se constituyen en un palimpsesto de significados, ninguno de ellos considerado como subalterno, que estarán presentes en cada uno de los capítulos de este artículo.

Concordamos con Montalvo y Silva (2009), que son numerosas las maneras de situar un estudio ambiental de estos ecosistemas litorales. Principalmente el análisis de este espacio costero del norte semiárido, se sustenta en la convicción de una innecesaria dicotomía entre ambiente y sociedad, en la medida que todos estos espacios se co-construyen desde y con la población que forma parte de su ecosistema.

\footnotetext{
Si el espacio es un ambiente, un ecosistema, él no es un ambiente natural dado, más un ambiente cognitivamente aprendido y culturalmente construido, es un espacio "significado", cuyo uso social le atribuye un sentido. La noción de ambiente incluye, entonces, las relaciones sociales y la cultura que hacen de la "población" de ese ecosistema una sociedad (Woortmann 2007: 481).
}

Ingold (2013) por su parte, enfatiza en esta mirada acerca de la relación sociedadambiente, proponiendo la idea de reciprocidad entre persona y ambiente, sustentada en el conocimiento directo que adquieren durante el transcurso de sus actividades cotidianas, de este modo se construye y se asienta un modelo consuetudinario de prácticas (Skewes et al. 2012) y, por qué no también de miradas acerca de estos espacios marítimos, no tan solo en sus poblaciones de pescadores, sino que en los demás habitantes del pueblo.

Es por ello que proponemos la existencia de una memoria, que llamaremos inicialmente ecosistémica, en los habitantes de Los Vilos, entendida desde el concepto ecológico de nicho, definido como ese "pequeño rincón del mundo ocupado por un organismo, al cual se integró a través de un proceso de adaptación" (Ingold 2013: 133), proceso que se desarrolla como una respuesta adaptativa pero también simbólica y estratégica de su población humana, que no se puede soslayar.

Dos perspectivas logran ser visualizadas a partir de la idea de nicho, por una parte la importancia del litoral del norte semiárido, situándolo en un contínuum anclado en una tradición marítima prehistórica, visión a la cual se adscriben principalmente sus pescadores, 
mientras que, en paralelo, su población urbana, no dedicada a las actividades pesqueras, reitera una historia más reciente asociada al puerto como espacio de confluencia de actividades mineras, agrícola-ganaderas y pesqueras (siglos XIX y XX). Ambas perspectivas permiten poseer una visión histórica de este litoral, visualizando sus habitantes el futuro de Los Vilos, como un polo industrial y turístico que las reúne.

Si bien esta investigación se beneficia de marcos teóricos como son la antropología marítima y los estudios sobre la memoria e identidad, es desde una quizás revisitada concepción de historia ambiental donde se asienta más cómodamente. Esta sostiene que todo conocimiento sobre el ambiente esta socialmente construido y es históricamente contingente (Cronon 1993), entendiendo que la categoría de naturaleza es fundamental para el análisis histórico del ambiente haciéndose cargo, interdisciplinariamente, de ese vaivén entre las ciencias sociales y naturales que justifica su estudio (sensu Worster 1989), logrando así la construcción de una síntesis acerca de los procesos ecológicos, geográficos, económicos y también antropológicos (Cronon 1993).

A su vez, concordamos con Worster (1989), que la historia ambiental ha traspasado múltiples barreras, rechazando la premisa que la experiencia humana se encuentra al margen de restricciones naturales, constituyéndose en una especie separada y "supernatural", y que las consecuencias ecológicas de sus proezas de ayer pueden ser ignoradas. De esta manera, esta nueva aproximación a la historia ha tenido, al menos, tres importantes implicancias para las ciencias sociales: 1) haber cuestionado la idea del dualismo entre sociedad y naturaleza, 2) haber alertado sobre posibles escenarios socio-políticos y ecosistémicos presentes y futuros frente a la crisis ambiental (Evenden 2004; Pádua 2010) y 3) haber establecido un diálogo, aproximando saberes y miradas entre múltiples áreas disciplinarias de la ciencia social y la ciencia natural acerca de ese ambiente, ya no entendido como dual (Worster 1989).

Otra perspectiva complementaria la entrega la antropología marítima, al proponer que los cambios de las sociedades litoraleñas y sus modos de diferenciación, "están sustentadas en el estudio de las condiciones materiales, sociales y simbólicas de ocupación, de explotación y de gestión de recursos marítimos y litorales" (Geistdoerfer 1984: 10). Es principalmente desde una de las corrientes de la antropología marítima contemporánea que se instala la premisa que los pescadores se encuentran, casi siempre, directamente sometidos a las exigencias de una economía capitalista (Allegret 1989), confirmando con ello el relato de las vicisitudes que se exacerban en la economía del litoral de Los Vilos, a partir de fines del siglo $X X$, al verse despojados de sus territorios extensivos de pesca.

Los recuerdos de los vileños se adicionan y complementan en relación al litoral en el que habitan. Es en este sentido que Candau reconoce que la noción de "marcos sociales de la memoria" es más convincente que la de memoria colectiva. "Parece indiscutible que completamos nuestros recuerdos ayudándonos, al menos en parte, con la memoria de los otros" (Halbawchs 1994: 21 Cit. en Candau 2002). En los relatos vileños, también adquiere relevancia su condición de tránsito, bisagra entre la zona norte y la zona central, puesto que se rescata la importancia de su posición en el litoral de la provincia del Choapa: 
Es un punto de encuentro de gente que va de paso, lo que hace que los vileños tengan intercambios y eso hace que sean extrovertidos, porque el sol se esconde en el mar, en cambio en el interior la gente es más retraída, ve esconderse temprano el sol en los montes. Todo eso hace que cuando viene lluvia los espíritus se trastocan.

De este modo, la relación con el mar se manifiesta, en las comunidades pesqueras, en una serie de prácticas y representaciones simbólico-rituales, a la vez que como una fuente de procesos y recursos, donde se articula memoria y futuro. Memoria que puede ser entendida como categoría social construida, pero también omitida o abusada en su uso (Jelin 2001), omisión que se presenta en algunos relatos vileños en relación a ciertos temas asociados a conflictos entre la comunidad litoraleña y la minería.

\section{Material y métodos}

Este trabajo corresponde a un estudio preliminar acerca de la historia del litoral de Los Vilos y se ancla en los recuerdos del pasado conocido, que han sido rescatados de las entrevistas a los habitantes de Los Vilos, complementadas con documentos históricos, cartográficos y fotográficos que se encuentran en archivos nacionales (SHOA, Museo Histórico Nacional, Biblioteca Nacional, Archivo Nacional, Biblioteca Municipal de Los Vilos, colección particular en Los Vilos), junto con bibliografía arqueológica, histórica, botánica, pero también literatura vileña (Tapia 2012; Contreras y González 2014 entre otras)

En relación a este palimpsesto de conocimientos académicos y locales (sensu Briones 2013), concordamos con Le Goff (1982), al proponer que no hay que olvidar que la oralidad y la escritura se reúnen en general en la sociedad y que esta coexistencia es bastante importante para la historia. En este sentido Goicovic (2013) construye un importante, exhaustivo e insoslayable relato acerca de la historia de Los Vilos, al cual incorpora testimonios orales de sus habitantes.

Para esta investigación se contó con dos libros publicados que relatan la historia de la pesca en Los Vilos, uno de ellos se construye como una historia de vida, transcrita y editada por una antropóloga (Raúl Tapia, en Fuenzalida 2016), al cual se une el relato histórico-fotográfico y principalmente autobiográfico de Juan Carlos Delgado (2017). Este último se complementó por una entrevista, efectuada en julio 2017, que permitió evidenciar y reiterar los elementos esenciales que construyeron su relato escrito acerca de la historia de los pescadores de Los Vilos.

Todos estos antecedentes sobre el habitar costero y sus actividades asociadas, fueron además complementados con ocho entrevistas focalizadas principalmente en la visión histórica de su litoral que poseen los otros habitantes de Los Vilos, entrevistándose a funcionarios públicos (2) y vecinos insertos en las áreas de la educación, cultura, comercio, turismo, religión y agricultura (6). Parte de esas ocho entrevistas acompañan y complementan el presente artículo.

Las entrevistas fueron en su totalidad transcritas, utilizando además las pautas éticas del código de la antropología en Chile y de Fondecyt (consentimiento informado escrito, anonimato de las fuentes y omisión de pasajes de la entrevista si así lo solicitaba el informante). Además, se estableció con la mayoría de ellos una relación de reciprocidad ("vuelta de 
mano"), que significó la entrega editada de las entrevistas bajo la forma de un cuadernillo impreso al cual se le agregó información histórica que era específica de su interés o, su entrega vía correo electrónico.

A partir detodos estos antecedentes recopilados, el presente trabajo puede proponer que existe una negación de la discontinuidad entre pasado y presente (Castillo 2007), aportando esta información a la formulación de una memoria de su ecosistema litoral construida latamente, desde el Pleistoceno superior, con grupos de cazadores-recolectores terrestres transitando por los sectores aledaños a la costa actual (sitios paleoindios de Santa Julia, Quereo), comunidades de pescadores-recolectores marinos pertenecientes al Holoceno inicial (sitios huentelauquen), comunidades históricas (changos), hasta llegar a las actividades pesquero-artesanales contemporáneas.

Son éstas últimas las que se sienten depositarias de tradiciones canoeras de raigambre nómade, asociadas a prácticas que se ven abortadas en la actualidad y que tuvieron una importancia comercial para Los Vilos, como asentamiento urbano durante el siglo XX.

\section{El ecosistema de Los Vilos}

El norte semiárido de Chile abarca desde el norte del río Aconcagua hasta la región de Chañaral. Los Vilos está ubicado en la provincia del Choapa y las comunas que la componen son Canela, Illapel, Salamanca y Los Vilos.

El clima en Los Vilos presenta una gran variación térmica entre verano e invierno, considerado de estepa local con influencia costera. Durante todo el año las precipitaciones no son altas, siendo de $213 \mathrm{~mm}$ al año. En Los Vilos, la temperatura media anual es de $17^{\circ} \mathrm{C}$.

En las entrevistas efectuadas a funcionarios públicos y profesor se recalcaron las diferencias que alberga la comuna de Los Vilos. Ella está compuesta por la cuenca de Pupío por el norte y la cuenca del Quilimarí por el sur, ambas de tendencia muy diversa. Mientras la de Pupío corresponde a un espacio principalmente de raigambre minera que posee un claro problema ambiental e hídrico, dado que no existen aportes de nieve para la importante necesidad acuífera de la industria minera, en el caso de Quilimarí se trata de una cuenca principalmente agrícola, con el desarrollo de un turismo de intereses especiales asociado a los yacimientos de cuarzo. En la comuna existen muchas localidades rurales que se sitúan principalmente en el interior, siendo mencionadas las de Caimanes, Guangualí, Pupío, Quilimarí, Tilama, Quelón, Los Cóndores, Cerro Blanco, Los Maquis, Infiernillo, Culimo, El Llano, El Manzano, entre otros (figura 1).

En líneas generales la vegetación de Los Vilos forma parte del conjunto característico de la Región Vegetal de Matorral y Bosque Esclerófilo (Gajardo 1994), con elementos florísticos propios de la subregión de matorral estepario (e.g. Schinus latifolius, Podanthus mitiqui) y, en particular, de la formación matorral estepario boscosa de distribución exclusivamente costera.

Una singularidad del Norte Chico está constituida por la presencia de bosques de carácter relictual o azonal (hacia el sur de los $30^{\circ} \mathrm{S}$ ). Así, por ejemplo, en la zona del Limarí y Quilimarí es posible encontrar bosques relictos dependientes de las neblinas costeras, dominados por olivillos (Aetoxicon punctatum) y petrillos (Myrceugenia correifolia). También en las zonas costeras del Choapa 
Figura 1. Área de estudio

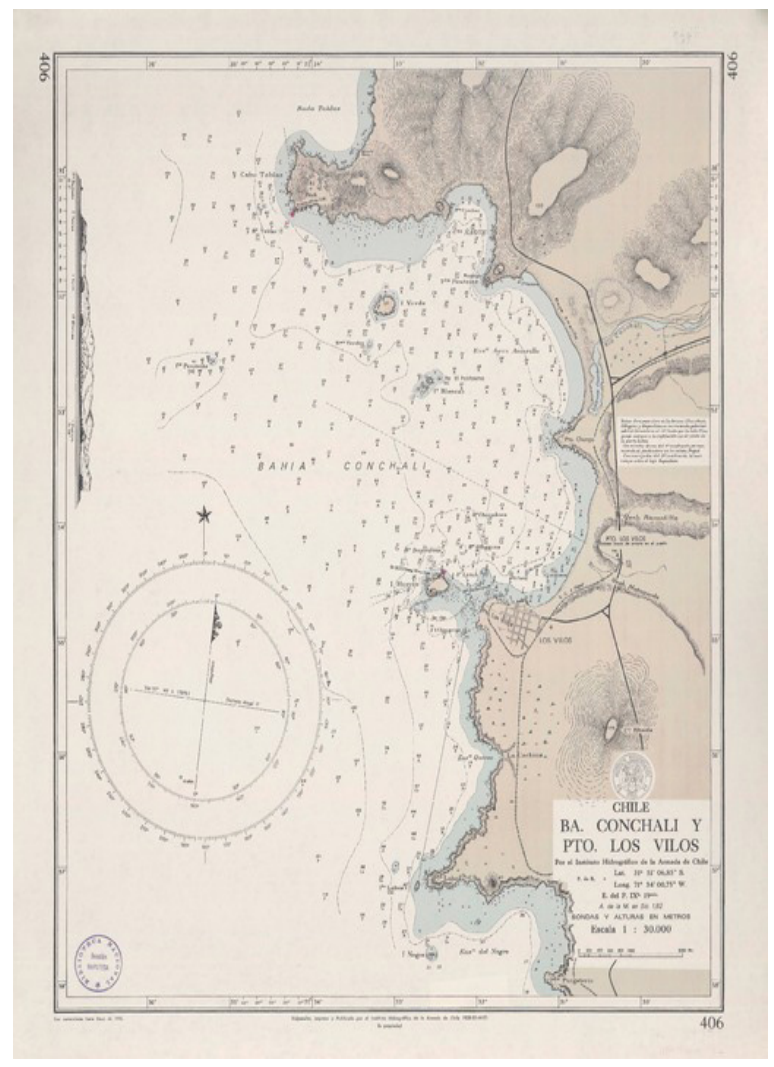

Fuente: Bahía Conchalí i Puerto los Vilos [material cartográfico] por la Marina de Chile. Mapoteca. Disponible en Biblioteca Nacional Digital de Chile http://www.bibliotecanacionaldigital.cl/bnd/631/ w3-article-157214.html Accedido en 23/3/2018.

principalmente, se encuentra una serie de bosques pantanosos dominados por myrtáceas y canelos (Drimys winteri), que se desarrollan en lugares donde aflora la napa freática (Maldonado et al. 2016: 31).

En este contexto, el estudio fitogeográfico de especies leñosas del litoral vileño (Solari y Gajardo Ms), mostró un conjunto de taxas que fueron colectados en diversos ecosistemas presentes en las proximidades del litoral y sus valles costeros (Quereo, Quebrada Mal Paso, Fundo Piedra Amarilla). Todos ellos confirman una gran diversidad de especies, donde es importante destacar la conjunción de elementos endémicos de la zona central de Chile, siendo un $44 \%$ de los taxones identificados exclusivos de la zona centro y centro sur de Chile (Hoffmann 1998), en tanto que especies como Fuchsia lycioides y Pouteria splendens crecen exclusivamente en las regiones IV y $\mathrm{V}$ entre los 30 y $33^{\circ} \mathrm{S}$ (Hoffmann 1998; Hechenleitner et al. 2005).

Esta situación, posiblemente de riqueza ecotonal, es corroborada por la observación directa de un profesor de los Vilos "esta es una zona transicional, de vegetación relicta de maitenes, arrayanes, molles ..."

A su vez, su relato demuestra estar consciente de la pérdida de las especies a lo largo del tiempo, debido a diferentes fines, no sólo locales y que involucran el pasado de Los Vilos como puerto menor:

\section{De aquí se exportó mucha leña de espino que hoy día no está (...) Si encontramos quebracho, paihuen, tara muy poca. La tara estaba en esta zona y fue muy usada para el tanino. Para sacarle taninos, para teñir cueros y géneros y la hicieron desaparecer.}

Entonces, uno de los elementos a retener en relación a la vegetación de la zona es la desaparición de la flora local muy tempranamente, debido a su explotación:

Según ciertos autores, el puerto de Los Vilos, se fundó para proveer carbón de piedra nacional a las minas de cobre de Aconcagua, cuando se agotaron o se prohibió la explotación de las maderas de los montes y la chamiza de los valles (Barros 1986: 57 Cit. en Avilez 2015: 58). 


\section{Prehistoria del norte semiárido costero.}

El norte semiárido costero ha variado en el tiempo, geo-climática y culturalmente. Ambas son razones que justifican explicitar las diferentes estrategias adaptativas que se instalaron durante el tiempo humano conocido de este nicho (sensu Ingold 2013).

En los testimonios escritos $u$ orales de los pescadores vileños, se reitera lo nómade y lo chango como categorías que ya sea sienten como suyas o son estratégicamente de reciente apropiación. Cuáles de estas formas de vida han perdurado, hasta cuándo, son interrogantes que hacen necesario entenderlas en la historia del habitar de este norte semiárido. Esto implica remontarse a las primeras incursiones que efectuaron sus habitantes a la costa durante el Pleistoceno tardío, hasta la instalación de poblaciones de cazadores recolectores marinos y de sociedades agro-alfareras, a lo largo del Holoceno.

La historia cultural del norte semiárido se ancla muy tempranamente, en el Pleistoceno final (aprox. 11.000 AP), con un campamento de ocupación efímera (Jackson et al. 2007) llamado Santa Julia, ubicado al norte de Los Vilos y distante $8 \mathrm{~km}$ de la costa pleistocénica. Se trata de "... uno de los sitios con precisas evidencias culturales asociadas a fauna extinta en estratigrafía" (Nuñez et al. 2016: 87).

Un elemento a destacar, que demuestra la aproximación de estas comunidades de cazadores recolectores a una costa más propicia de habitar, es un temprano mejoramiento climático en la zona, propio de la transición Pleistoceno - Holoceno, que lo muestra la instalación temprana de especies propias del norte semiárido actual, como es Guayacán o Palo Santo (Porlieria chilensis), especie descrita en el estudio arqueobotánico del sitio de cazadores-recolectores pleistocénicos de Santa Julia (Solari y Gajardo Ms).

En paralelo, en una zona lagunar costera ubicada al sur de Los Vilos, se encuentra el sitio paleoindio de Quereo. En él, además de megafauna hoy extinta, se encontraron dos conchas de locos, lo que demuestra una incipiente relación con el mar que paulatinamente se constituye en un espacio posible de visitar, situado en ese momento a una distancia mucho mayor del campamento. Se trata por tanto de un paisaje pleistocénico diferente, cuyo testimonio actual es la presencia, en estas terrazas costeras, de varios sistemas de paleodunas, algunas erosionadas y removilizadas de manera eólica. (Cornejo et al. 2016).

Berenguer et al. (2008) propone que tempranamente existiría una "conquista económica del mar" en el semiárido chileno y posiblemente se establecen así los justificativos de pertenencia identitaria retomados por las actuales poblaciones de pescadores en la zona, quienes en sus relatos reiteran elementos que adscriben a un nomadismo estacional o de corta duración (sensu Jackson 1999 en Cornejo et al. 2016), anclados en una realidad histórica de larga data, que se perpetua no tan solo allí, sino que a lo largo de la costa chilena.

Esta permanencia prolongada (estacional) o, de corta duración en el área, se daría inicialmente durante el Holoceno temprano en base a dos patrones de asentamientos que podrían, para Maldonado (1999), estar en directa relación con las características fitogeográficas y climáticas de la zona. La primera se daría entre 10.000 y 
9.000 años A.P. y entre 4.000 y 1.850 años A.P; mientras que la segunda 6.700 a 4.000 años $14 \mathrm{C}$ A.P. y con posterioridad a los 1.850 años 14C

La cultura Huentelauquen (aprox. 9.500 a 7.000 años $\mathrm{aC}$ ), muestra los inicios de esta tradición litoral en el norte semiárido, extendiéndose desde la región de Antofagasta hasta Pichidangui. Lleva su nombre porque en la desembocadura del río Choapa, en la zona homónima, se descubren evidencias de ocupación humana de cazadores recolectores marinos con presencia de artefactos, como son piedras de moler, testimonios de una recolección terrestre junto a pesas de red para la pesca. A la vez se encuentra asociado a varios entierros y desechos del desconche.

En relación al litoral, esta permanencia en el tiempo de estrategias socio-económicas asociadas a la recolección marina, continúan durante el Holoceno medio en la costa de Los Vilos, con dos modalidades propias de un tipo de asentamiento y economía de grupos colectores, que poseen sincrónicamente bases residenciales y campamentos de tareas principalmente de recolección y desconche de moluscos situados en los acantilados adyacentes al litoral (Cornejo et al. 2016). Esta estrategia evoca lo que los pescadores actuales relatan y perpetúan sobre sus faenas costeras (presencia de caletas y de varaderos como espacios esporádicos de pesca y recolección marina).

Durante el Holoceno tardío (2000 y 0 años aC), sus más de 80 sitios costeros poseen para los arqueólogos un amplio espectro económico. Se trata en su mayoría de extensos conchales que atestiguan una enorme ocupación humana a lo largo de la costa, con la explotación de especies litorales principalmente moluscos (Cornejo et al. 2016). Dentro de esta economía marítima, a partir del 200 d.C., "pescadores tardíos dominan la extensión del mar a través del uso de embarcaciones" (Berenguer et al. 2008: 22). Para Jackson y otros autores (1999 en Cornejo et al. 2016), este complejo no estaría solo relacionado con la costa y las actividades marinas, sino con un modelo de movilidad y circulación de materias primas que involucra las áreas de tierras interiores, cuyos testimonios están dados por los restos óseos de camélidos, cánidos y roedores, entre otros.

Muy posteriormente, con la llegada del período formativo ( $300 \mathrm{aC})$, se confirma una clara relación entre los espacios litorales y las sociedades agro-alfareras asentadas principalmente en los valles transversales, construyéndose en estos corredores biogeográficos (E-O), una movilidad e intercambios costa-valles. Estas estrategias pueden ser relacionadas primero con elementos de la cultura El Molle (tembetás, pipas y cerámica) y posteriormente por las culturas Las Ánimas y Diaguita (Cornejo et al. 2016).

De este modo, la memoria de las relaciones existentes entre estos ecosistemas posee larga data y continúa en el siglo XIX con la denominación oficial de Los Vilos como puerto menor, justificado por el comercio de las materias primas asociadas a la minería y lo agro-ganadero de los valles interiores de Illapel, Salamanca y otros. ${ }^{1}$

Probablemente lo interesante de la historia de esta costa semiárida lo constituye el cómo perduran y se suceden en los espacios litoraleños grupos que retoman estrategias los

La voz de Illapel, agosto 25 de 1944 
unos de los otros, no perdiendo ese carácter nomádico, hasta finales del siglo XX. Se instala así una tradición de movilidad en la economía de base pesquera-recolectora que se perpetúa y que se encontrará en los testimonios de pescadores que describen los espacios de recolección y pesca marina, principalmente durante el siglo XX, y de su tránsito por gran parte del litoral chileno, que los lleva incluso hasta la zona sur-austral (Valdivia y espacios costeros de Patagonia septentrional).

\section{Lo chango desde la historia.}

Los escritos y entrevistas efectuadas a pescadores y población vileña aluden a la denominación de chango como parte de su memoria ecosistémica, correspondiendo esta tradición a diferentes grupos históricos de economía marítima de la región norte y de valles transversales, que se reúnen a partir del siglo XVII bajo esta denominación (Berenguer et al. 2008).

En las primeras décadas del siglo XX, la tradición "changa" de pescadores recolectores del litoral norte de Chile, ocuparía las costas desde Los Vilos hasta Chañaral de las Ánimas, identidad que es descrita en diversas crónicas de su historia post-contacto (Frezier 1902; Latcham 1910; Berenguer et al. 2008; Cornejo et al. 2016).

(...) descendientes de estos se hallan hasta el presente, diseminados por distintos puntos de la costa, en las pequeñas caletas alejadas de los centros de población (...) Han ocupado su presente habitat por muchos siglos, i a ellos se deben los numerosos conchales de estas costas, antiguos i modernos, en todos de los cuales los restos hallados representan la misma cultura i manera de vivir. Todavía se dedican a la pesca, i usan balsas de cueros de lobos marinos inflados; pero se valen también de botes i lanchas de sistema menos primitivo. (...) Ahora aumentan sus recursos con pequeños cultivos; i con la mantención de manadas de cabras (Latcham 1910: 16-17).
Probablemente lo que mejor los distingue es su tradición tecnológica de utilizar las balsas de cueros de lobos infladas, las que se han anclado en la memoria a partir de los dibujos y descripciones en documentos históricos, que se reiteran a lo largo del período histórico desde Perú hasta la zona central de Chile.

\begin{abstract}
Para echar sus redes al mar, los pescadores se sirven de balsas, en vez de botes. Estas son dos grandes vejigas alargadas, llenas de aire, hechas de piel de lobos marinos, tan bien cocidas que un peso por considerable que sea, no es capaz de hacer salir el aire, pues hai en el Perú algunas que llevan a doce i medio quintales o cincuenta arrobas, (...) i con un pequeño remo de dos palas, un hombre se coloca encima, i si el viento puede servirle, coloca una pequeña vela de algodon. En fin, para reemplazar el aire que puede escaparse hai adelante dos tripas por las cuales se sopla en las vejigas o globos cuando es necesario (Frezier 1902: 106)
\end{abstract}

Esta balsa permite el transporte humano a su vez que el de mercancías. A partir de los archivos de los Anuarios de la Marina, Páez (1986), propone que su uso comercial se detiene hacia 1880 , siendo reemplazadas en las zonas portuarias y de pesca por otro tipo de embarcaciones menores, pero no terminando del todo su uso doméstico. Esta tecnología aún se mantuvo de manera residual hasta mediados del siglo XX cuando el arqueólogo $\mathrm{H}$. Niemayer solicita a un pescador de Chañaral que le confeccione una balsa (Carmona 2003).

\begin{abstract}
En el año 1965 Niemayer tomo contacto con don Roberto Álvarez conocido en la zona de Chañaral, como "el chango", a quien le solicitó la construcción de una balsa (...). El Sr. Álvarez recordaba la técnica de construcción que le había enseñado su padre y accedió a la petición de Niemayer, concluyendo la construcción de ésta en abril del mismo año. Posteriormente se realizó una prueba de navegación y luego fue trasladada al Museo Arqueológico de la Serena, donde se conserva hasta la actualidad².
\end{abstract}

http://www.mnhn.cl/613/w3-article-35338.html?_noredirect=1 (revisado 28/03/2018) 
Paradojalmente, es a través de este elemento de la cultura material que don Felipe Rivera, presidente de la Agrupación Cultural Changos, descendiente del último constructor de balsas de cuero de lobo don Roberto Álvarez, aseguró que "hace unos cuatro años nos organizamos como familia Álvarez Hidalgo y reconocimos la presencia de los changos entre nuestros ancestros..." (Reunión en Comisión Derechos Humanos, Senado de la República, 28 junio 2018).

Florido del Corral estudiando la patrimonialización de la cultura pesquera en Andalucía, propone al respecto que detrás de cada elemento cultural, como puede ser una canoa (sensu Malinowski 1922) “... se esconde un conjunto de prácticas, representaciones mentales, valores socialmente establecidos, instituciones de ordenación social (...) a tener en cuenta..." (2003: 30)

Los avatares de este proceso de reconocimiento del pueblo chango por el Estado chileno están resumidos en el Boletín 11188-17 del Senado de Chile, en el cual entre 06/04/2017 y 02/04/2019 se encuentran referidos dieciséis trámites constitucionales, desde el ingreso del proyecto a la Cámara de Diputados: "Modifica la ley $\mathrm{N}^{\circ} 19.253$, que establece normas sobre protección, fomento y desarrollo de los indígenas, y crea la Corporación Nacional de Desarrollo Indígena, para reconocer al pueblo chango como etnia de Chile", hasta un nuevo plazo para indicaciones, como segundo trámite constitucional, el cual se encuentra actualmente en el Senado.

Esta tradición cultural de la costa de la III y IV región de Chile, permite que los pescadores actuales vileños más tradicionales, también se sientan depositarios de la tradición marítima de pesca y recolección de larga data, que la sitúan como propia de los changos, siendo ésta la identidad que rescatan en sus escritos (Fuenzalida 2016; Delgado 2017) y que está presente en los relatos recopilados.

En sus testimonios justifican esta tradición, anclándola en la historia de la actual caleta San Pedro de Los Vilos, cuando ésta se llamaba Puerto Canoa y la residían sus antepasados.

Mi bisabuelo pillaba pescado con arpón en la orilla del mar ... salían a pescar en canoas de cuero de lobo marino... Dicen que esos viejos pescadores eran los indígenas del mar: los changos... así que tal vez nosotros también seamos changos. (R. Tapia, en Fuenzalida 2016: 18)

Esta perspectiva, ese "tal vez" de Raúl Tapia, le permite enfatizar a otro entrevistado que "el pescador es un nómada, era un nómada, de los años inmemoriales ... el chango andaba por toda la orilla del mar". Esta convicción les permitía ser libres de transitar.

(...) si aquí estaba malo, nos trasladábamos a otra caleta ... En ese tiempo no eran caletas, eran varaderos (...) En una caleta hay una organización. Un varadero es cuando uno llega esporádicamente ahí, se estaba un tiempo y después se iba a otro lado, desaparecía y no quedaba nadie.

La movilidad de los pescadores de Los Vilos los lleva lejos, no sólo a los 12 varaderos, convertidos posteriormente en caletas entre el río Limarí y Pichidangui, donde se trasladaban y "trabajaban tranquilos", sino que Juan Carlos Delgado en su libro autobiográfico, agrega que: "en la llamada fiebre del loco en el año 1986 ... nos llevaron a un grupo de la caleta a la Décima región (2017: 26-27)3.

En la visita a Valdivia de don Juan Carlos Delgado, (octubre 2018), para lanzar su libro en la UACh, apoyado por el Fondecyt 1171309 , se encontró con un pariente que, desde esos viajes como pescadores al sur, decidió establecerse en Niebla (Valdivia), como otros. 
La llegada de estos grupos "nortinos" de pescadores y buceadores ha quedado en la memoria de los habitantes de Calbuco, quienes no identifican fehacientemente en sus relatos si éstos son de la zona de Valparaíso, San Antonio o más al norte, pero recuerdan claramente las oleadas de ellos que desembarcan en Calbuco, espacio importante de conserveras de mariscos y de otras especies, como también del desarrollo de la pesca de la merluza austral en los años 80' en las costas de la Patagonia septentrional.

\section{7. "Se terminó el peregrinar del pescador por las caletas"}

Ahora bien, ¿por qué ellos se sienten parte de esa identidad propia del pueblo chango?

Una de las principales características de la tradición cultural de estos grupos históricos es la movilidad, la que se reactualiza en el imaginario de sus comunidades costeras contemporáneas y se ancla en el uso extensivo del litoral durante el siglo XX, relatado en sus escritos y entrevistas. A su vez poseen una doble pertenencia, a caletas urbanas en paralelo a fondeaderos o caladeros rurales, espacios por los cuales podían transitar libremente de acuerdo a la oferta de especies, estacionalidad y oportunidades varias.

Esta estrategia, propia de un nomadismo quizás un tanto idealizado en la actualidad, ha sido probablemente exacerbada y anclada aún más, en base a las enseñanzas de la historia de Los Vilos y, en ese contexto, el importante rol cumplido por la arqueología, del cual aún hoy dan testimonio.

Aquí han trabajado arqueólogos de renombre, cómo Lautaro Núñez de la Universidad del Norte y como Donald Jackson que hasta hace muy poco trabajaba acá en la zona.
Sus excavaciones en el litoral de Los Vilos han sido socializadas en toda la comunidad vileña, lo que ha producido una toma de conciencia bastante generalizada acerca de la prehistoria de la zona. Prueba de ello es también lo que testimonia la figura de un "mastodonte", animal extinto del pleistoceno superior y presente en el sitio arqueológico paleoindio de Quereo, que se erige como estatua en la ciudad (imagen 2)

Imagen 2. Estatua de Cuvieronius sp. (mastodonte) en Los Vilos.

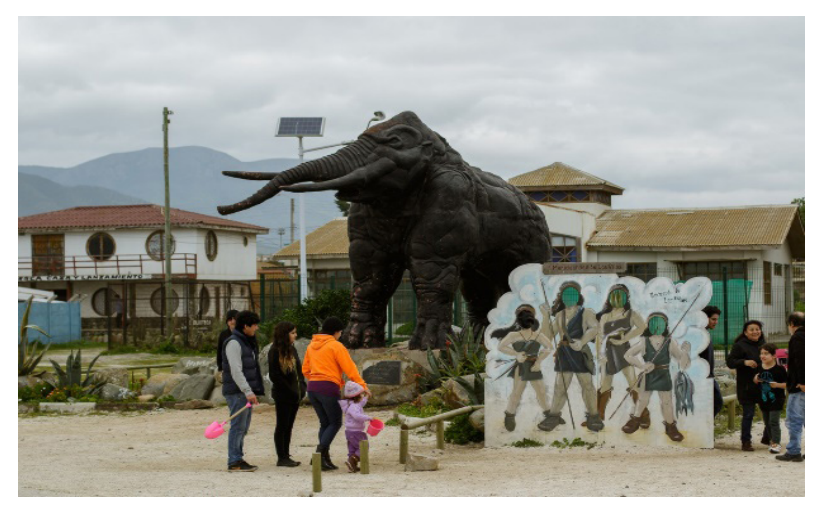

Fuente: Foto Alex Utreras.

Esta percepción esencialista de libertad y movilidad que reiteran los pescadores, fue abortada a fines del siglo pasado, donde estos vaivenes se detienen porque "el mar siempre fue libre y de todos los chilenos ... hasta que hicieron la famosa Ley de Pesca. Con eso, el mar quedó sólo para algunos pocos: para los industriales" (R. Tapia, en Fuenzalida 2016: 72), porque también las especies comienzan a escasear y aparecen las vedas. A su vez, para los pescadores desde los años 90' se adiciona el establecimiento de regulaciones, como son las áreas de manejo y la mutación de los varaderos en caletas, por tanto, con una organización que 
prohíbe estos espacios a quienes no pertenecen (Imagen 3).

Y ahí el pescador quedó estancado. Se terminó el peregrinar del pescador por las caletas. El pescador de Caleta San Pedro, Caleta San Pedro. Totoralillo, Totoralillo antes no, San Pedro, Totoralillo y Las Conchas era una sola cosa, usted saltaba de aquí para allá y nadie le decía nada.

De este modo se instala en los relatos de pescadores un pasado productivo en el litoral del Choapa.

(...) fue lo más bonito, porque había pesca, había de todo. Éramos libres para vivir como nuestros antepasados, que vivíamos de caleta en caleta. Eso, no sé si estará bien.

Imagen 3: Área protegida de recursos bentónicos de Caleta San Pedro.

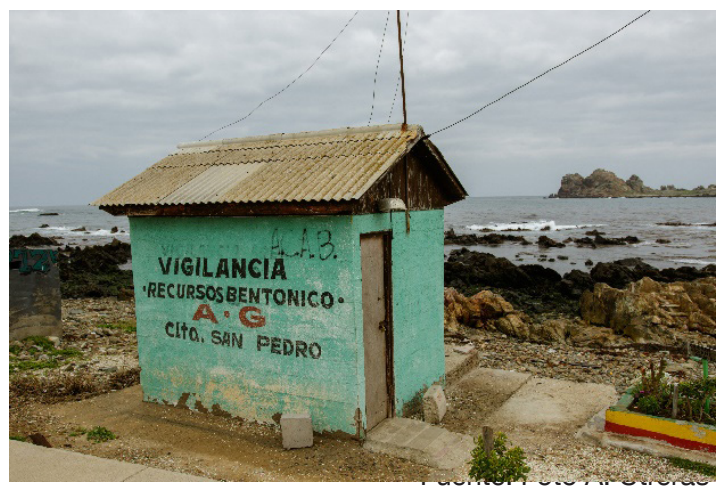

Ese pasado de la pesca artesanal, que permitía a los diarios de la época describir su riqueza comercializada, ha perdurado en la memoria del pescador.

En la actualidad la industria y su comercio es explotado por insignificantes capitales y obtienen ganancias fantásticas al traer y acarrear esos productos a Valparaíso o para Santiago. En el puerto de Los Vilos se encuentra: los erizos amarillos, la yerguilla para caldillos, la corvina etc etc - $y$ hasta un poco de congrio.

En el Puerto Oscuro hay una jaiba grande del porte de casi una langosta; una variedad de pescados riquísimos muy poco conocidos por los porteños por tratarse de un pescado que solo lo sacaron los japoneses en los años 1921, 1924. (La voz de Illapel, agosto 25 de 1944)

Algunos de los factores que aluden los pescadores, para que esta añorada estrategia terminara, fue la llegada de nuevas formas de pesca y recolección, asociadas también a las llamadas áreas de manejo, justificadas e insertas en la Ley General de Pesca y Acuicultura (1989 modificada el 2013).

(...) pasó que nosotros mismos nos echamos la soga al cuello. Porque fuimos pidiendo lugares. Pedíamos lugares, pero no pensábamos dónde trabajar. Y se fueron pidiendo, pedían aquí y después pidieron aquí, etc. y cuando nos vinimos a dar cuenta y ¿dónde vamos a trabajar? Porque en el área de manejo, la palabra lo dice manejo, hay que manejar el producto y uno no, estaba acostumbrado a trabajarlo.

Para algunos su pertenencia a un área de manejo, los "fijó" a un espacio determinado, a las caletas, uniéndose a esta nueva modalidad impuesta, la desaparición de especies marinas debido a su sobre-explotación, que desde los años 70' - 80' se venía observando.

Esta pérdida fue paulatina, a la vez que se fueron descubriendo otras especies que pudieron ser comercializadas gracias a una demanda externa (Santiago, Valparaíso), como es el caso del loco (Concholepas concholepas), poco explotado y poco apreciado en sus inicios.

Recuerdo una especie que se perdió, la sierra, (...). Después se perdió la jibia (años 70-80), Con la jibia los viejos encarnaban los espineles. Después el jurel empezó a mermar a mermar. Los grandes pesqueros, lo grandes industriales, que están afuera, en las 200 millas y antes de las 200 millas le pillaban todo, todo (...) (Ellos) deben haber empezado cuando empezó la famosa ley de pesca. 
También en la extracción de mariscos, con la llegada del buceo profesional, sucede lo mismo: "Cuando ya éramos maestros del buceo, nosotros en lugar de sacar tres mil erizos, sacábamos seis mil. Así fuimos extrayendo hasta terminar con los bancos (...) trabajábamos sin ley" (R. Tapia en Fuenzalida 2016: 47).

Actualmente es la importante extracción de algas la que preocupa a los habitantes de Los Vilos (Imagen 4-5):

Se está tratando muy mal el mar porque antiguamente el mar botaba las algas en forma natural y ahora se meten a cortarlas y eso está produciendo un ataque al biosistema, al extraerlas de esa manera con estas formas de cortarlas (...). La gente se pregunta por qué el mar viene con tanto oleaje, tan fuerte y es porque no tiene lo que lo atajaba y eso nos está llevando a nosotros a perder todo lo que es la riqueza del mar.

\section{A modo de conclusión}

El análisis de diferentes perspectivas desde las que es posible construir la relación entre Los Vilos y su mar, permite evidenciar los consensos que potencian los relatos escritos $u$ orales de sus habitantes, en relación a los archivos arqueológicos, documentales y fotográficos, construyéndose un palimpsesto de significados que aportan a la construcción de la historia de este litoral.

El conjunto de estas manifestaciones, ayudan a reconstruir la configuración ambiental de la economía de base pesquero-artesanal de Los Vilos, cuyas raíces histórico-arqueológicas estarían asentadas en una cultura changa propia del litoral del norte semiárido, de la cual sus poblaciones pesqueras tradicionales se sienten depositarias.
Imagen 4 y 5: Embarque de algas para su comercialización en caleta San Pedro (Los Vilos)
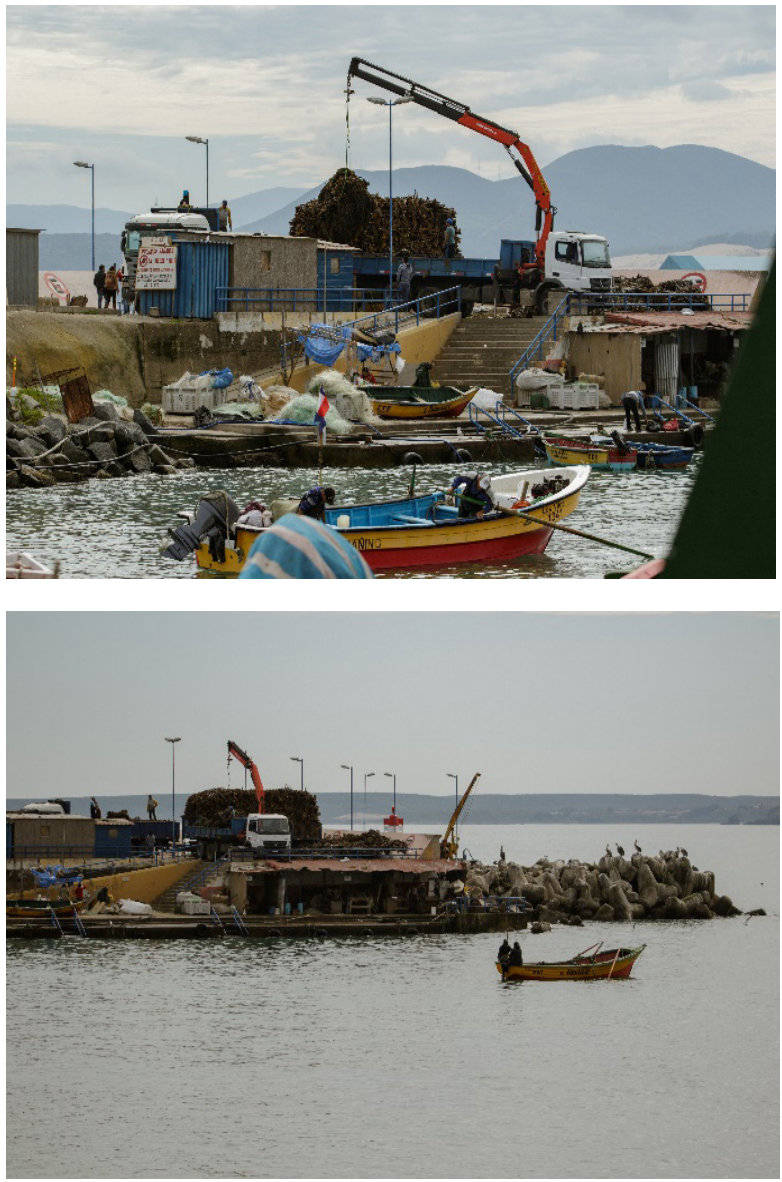

Fuente: Fotos de Alex Utreras.

Los diversos antecedentes expuestos permiten confirmar que existe una negación de la discontinuidad entre pasado y presente y que la reactivación de una identidad, cercana a la tradición del pueblo chango, puede ser efectuada a través de los marcos sociales de la memoria, los cuales son depositarios de una serie de prácticas adaptativas y simbólicas valoradas. Estas prácticas se encuentran asociadas a un 
ecosistema que continúan reivindicando como "su nicho" y así lo evidencian en escritos y relatos.

La ancestralización que se ve en escritos y entrevistas, puede ser entendida como una forma de "producir" una nueva concepción del litoral frente a la pérdida de especies marinas, la fijación a caletas y al daño ambiental.

De este modo, el pasado es entendido en libertad, sin leyes y sin control, mientras que el presente se explica en lo estático, en estar fijo en un solo territorio, la caleta y sus áreas de manejo, soluciones estratégicas directamente relacionadas con la "privatización" o "neoliberalización" del mar, donde en general, el futuro de la pesca artesanal es visto como:

(...) muy oscuro. Yo creo que nosotros como pescadores vamos bajando. Lo que si se ve es que el pescador va a tener que cambiar el chip ¿En qué? En el cultivo. Va a tener que ser como los agricultores. Tratar de cultivar porque la pesca cada día va bajando"

Tampoco es posible soslayar en los relatos de los pescadores cómo se instala una ambivalencia; a la añoranza de esa libertad perdida se une una clara conciencia del sufrimiento que implicaba esta actividad "(...) porque todo ese tiempo que estuve yo patiperrié mucho, sufrí mucho por las caletas, por los varaderos (...)"

Este sacrificado oficio es, en la memoria de los vileños urbanos, principalmente de sus comerciantes, el que enriqueció al pescador al mismo tiempo que "salvó" económicamente al pueblo, luego del cierre del puerto en la década del 50'.

Escuchar, leer y visualizar este palimpsesto de significaciones tanto locales como académicas no sólo da cuenta, sino que reactiva ese pasado histórico-ambiental de Los Vilos, a la vez que permite comprender su presente y entrega luces sobre un futuro deseado, que está basado en los anhelos de una reactivación económica como espacio pesquero-artesanal, a la vez que balneario turístico, como lo fue antaño.

Todos estos procesos se despliegan en un espacio que puede ser considerado en la actualidad, como un litoral depredado, reflejado en las pérdidas de sus especies marinas y también, en las vedas que los constriñen. A su vez, Los Vilos es considerado por muchos como un área costera catalogada como de "sacrificio ambiental", relacionado con los acuerdos tanto terrestres como litorales con las compañías mineras, principalmente Minera Los Pelambres, involucrada en proyectos público-privados, como son Somos Choapa y Somos Los Vilos, en que es visualizada, por autoridades, como un buen aliado para el desarrollo económico, educacional y turístico de esta comuna.

Este estudio corresponde a una primera aproximación sobre la historia del mar de Los Vilos reuniendo diversas fuentes complementarias para el análisis de una estrategia adaptativa específica que se perpetúa a lo largo del Holoceno hasta fines del siglo XX, la de pescadores-recolectores del norte semiárido y su uso extensivo del litoral. De manera complementaria, dentro del proyecto Fondecyt 1171309, existen estudios en curso que se insertan en el ámbito de la antropología económica y están relacionados con los procesos de depredación y los sistemas extractivos en el litoral de Los Vilos (Saavedra, Macías en revisión, Saavedra, Navarro aceptado), a la vez que la tesis de Espinoza (2019), permite ahondar en la relación entre empresa minera y pescadores. 


\section{Agradecimientos}

A los vecinos que aceptaron compartir sus recuerdos y perspectivas acerca de Los Vilos: don Juan Carlos, Sra. Berta, don Eduardo, don Jorge, don Ricardo, don Fernando, don Gabriel, don Hans (julio 2017). También a quienes me encaminaron, ayudándome a establecer los primeros contactos y el acceso a la literatura vileña.
En Calbuco a don Luis, don José Milton y don Manuel (sept. 2017), que permitieron relacionar las memorias litoraleñas del norte y del sur, las que enriquecen el desarrollo del Fondecyt $\mathrm{N}^{\circ}$ 1171309. Universidad Austral de Chile (Valdivia). A la dirección de la Revista Austral de Ciencias Sociales.

\section{A mi colega Dr. Hugo Romero-Toledo, por su} revisión crítica y aportes bibliográficos.

\section{Bibliografía}

Allegret, J.L. 1989. La antropología marítima como campo de investigación de la antropología social. Agricultura y Sociedad n52: 119-142.

Avilez, J. 2015. Participación del Choapa en la Guerra del Pacífico (1879-1884). Chile: Volantines ediciones. Colección Rumbo al Norte.

Berenguer, J., Sinclaire, C., Cornejo, L., Escobar, M. 2008. Pescadores de la Niebla. Los Changos y sus ancestros. Catálogo de Exposición. precolombino.cl (consultado 15 de marzo 2018)

Briones, C. 2013. "Conocimientos sociales, conocimientos académicos. Asimetrías, colaboraciones, autonomías". Desigualdades.net. Working paper n³9: 1-22

Candau, J. 2002. Antropología de la Memoria. Buenos Aires: Nueva Visión.

Carmona, J. 2003. Archivos de suelo. Hans Niemayer y la arqueología científica en Chile. Chile-Italia: Ediciones La HuellaEdiciones Logos Group.

Castillo Ruiz, J. 2007. "El futuro del Patrimonio Histórico: La patrimonialización del hombre". e-rph Revista Electrónica de Patrimonio Histórico, No 1: 36-49.

Cornejo, L, Jackson, D., Saavedra, M. 2016. "Cazadores recolectores arcaicos al sur del desierto (ca. 11.000 a 300 aC.)". Prehistoria en Chile. Desde sus primeros habitantes a los Incas Cap.VI. Falabella et al (eds.). Santiago: Ed. Universitaria: 285-318.

Cronon, W. 1993. The uses of environmental history. Environmental history review, 17(3), 1-22.

Contreras, R., González, D. 2014. Será hasta la vuelta del año. Bailes chinos, festividades y religiosidad popular del Norte Chico. Chile: Ediciones Consejo Nacional de la Cultura y las Artes (FONDART).

Delgado, J.C. 2017. Mi vieja caleta. Santiago: Apostrophes ediciones.

Espinoza, P. 2019. Análisis antropológico sobre los espacios de las mujeres en la economía costera de la comuna de Los Vilos, en la región de Coquimbo, Chile. El caso de las caletas Chigualoco y Huentelauquen. Tesis. Universidad Austral de Chile (Valdivia).

Evenden, M.D. 2004. Fish versus power: an environmental history of the Fraser River. Nueva York: Cambridge University Press.

Florido del Corral, D. 2003. Hacia una patrimonialización de la cultura pesquera en Andalucía. Debate e Investigación. PH44-julio 2003: 30-33

Frezier, M. 1902. Relacion del viaje por el mar del sur i las costas de Chile i el Peru durante los años de 1712, 1713 i 1714. Santiago: Imprenta Mejía.

Fuenzalida, A. 2016. El cabo de la vida. El siglo XX desde el mar. Chile: Donnebaum S.A.

Gajardo, R. 1994. La Vegetación Natural de Chile. Clasificación y Distribución Geográfica. Santiago: Editorial Universitaria.

Geistdoerfer, A. 1984. "Ethnologie des activités halieutiques". Anthropologie maritime. Description des proces de travail. Bulletin $\mathrm{n}^{\circ} 1:$ 5-10.

Goicovic, I. 2013. Pasando a la Historia. Los Vilos 18551965. Valparaiso: Impresión GSR. Disponible en: http://www. munilosvilos.cl/Publicaciones/LosVilos. Segunda Edición.pdf (consultado en mayo 2017).

Hechenleitner, P. et al. 2005. Plantas Amenazadas del CentroSur de Chile. Distribución, Conservación y Propagación. Primera Edición. Universidad Austral de Chile y Real Jardín Botánico de Edimburgo, Valdivia.

Hoffmann, A. 1998. Flora Silvestre de Chile, Zona Central. Edición 4. Santiago: Fundación Claudio Gay.

Ingold, T. 2013. Culture et perception de l'environnement. En T. Ingold Marcher avec les dragons. Francia: Ed. Zones sensibles. Cap. V: 131-148.

Jackson, D. et al. 2007. "Initial Occupation of the Pacific Coast of Chile during Late Pleistocene Times". Current Anthropology. 48 (5) 725-731 
Jelin, E. 2001. ¿De qué hablamos cuando hablamos de memoria? En: Los trabajos de la memoria. España: Siglo Veintiuno editores.

Latcham, R. 1910. Los changos de las costas de Chile. Santiago: Imprenta Cervantes.

Le Goff, J. 1982. Pensar la Historia. Barcelona: Ed. Altaya.

Maldonado, A. 1999. "Historia de los bosques pantanosos de la costa de Los Vilos (IV región, Chile) durante el Holoceno medio y tardío". Tesis Magíster. PG/028/97 Dpto. Postgrado y Postítulo, U. de Chile.

Maldonado, A. et al. 2010. "Early Holocene climate change and the human occupations of the semiarid coast of northern Chile". Journal of Quaternary Science. 25 (6): 985-988.

Maldonado, A. et al. 2016. "El escenario geográfico y paleoambiental de Chile." Prehistoria en Chile. Desde sus primeros habitantes a los Incas Cap. I. Falabella et al. (eds.). Santiago: Ed. Universitaria: 23-70

Montalvo, A. y Silva, F. 2009. El mar ¿territorio de quién? Algunos elementos para una propuesta de una antropología del litoral. Universitas humanística no. 68 julio-diciembre de 2009: 247-265.

Nuñez, L. et al. 2016. "Cazadores recolectores tempranos y los primeros poblamientos en Chile hacia finales del Pleistoceno (ca.13.000 a 10.000) Prehistoria en Chile. Desde sus primeros habitantes a los Incas Cap. I. Falabella et al. (eds.). Santiago: Ed. Universitaria: 71- 116

Pádua, J. A. 2010. As bases teóricas da história ambiental. Estudos avançados, 24(68), 81-101.

Páez, R. 1986. "Balsas de cuero de lobo en la segunda mitad del siglo XIX. Antecedentes cuantitativos para el norte de Chile".
Chungara n`16-17: 421-428.

Rivera, J. 2014. Historia de los puertos y caletas del norte de Chile (desde Arica hasta Papudo). Chile: Dirección General del Territorio Marítimo y de Marina Mercante.

Saavedra, G. y Macías Vázquez, A (en revisión). Territory, sustainability and inmaterial commons on the coast of Chile. Cutural Geographies.

Saavedra, G. y Navarro, M. (aceptado). Pesca artesanal, economía e intermediación en el litoral sur-austral chileno. Un análisis histórico-etnográfico con perspectiva latinoamericana. Estudios Atacameños.

Skewes, J.C., Álvarez, R., Navarro, M. 2012. Usos consuetudinarios, conflictos actuales y conservación en el borde costero de Chiloé insular. Magallania vol. 40(1): 109-125

Solari, M.E. y Gajardo, A. (Ms). Informe técnico. Antracología y análisis de fitolitos del sitio Santa Julia (área Quebrada de Mal Paso, Los Vilos). Fondecyt 1030585. No publicado.

Tapia, B. 2012. Crónica de Los Vilos. La memoria olvidada. Los Vilos: Ediciones Municipalidad de Los Vilos. Gobierno Regional de Coquimbo

Vidal Gormaz, F. 2013. Geografía náutica de Chile. Biblioteca Fundamentos de la Construcción de Chile. Santiago: Centro de Investigaciones D. Barros Arana, DIBAM.

Woortmann, E. 2007. Cambios de tiempo y espacio/cambios sociales, bajo el impacto de la modernización. Estudios feministas, vol. 15: 476-484.

Worster, D. 1989. The Ends of the Earth. Perspectives on Modern Environmental History. Nueva York: Cambridge University Press. Apéndice traducido del inglés, con autorización del autor, por Guillermo Castro Herrera. 
